\title{
Acumulación primitiva y acaparamiento de tierras en Colombia. Dinámicas del desarrollo*
}

Primitive Accumulation and Land Hogging in Colombia. Dynamics of Development

Álvaro Germán Torres Mora ${ }^{\mathrm{a}}$

Universidad de Tennessee, Estados Unidos

germantorresmora@gmail.com

ORCID: https://orcid.org/0000-0001-9759-9221
DOI: https://doi.org/10.11144/Javeriana.papo25.apat

Recibido: 15 Enero 2019

Aceptado: 11 Abril 2019

Publicado: 29 Junio 2020

\section{Resumen:}

En este artículo abordo la relación entre el acaparamiento de tierras, el cultivo de palma de aceite y el paramilitarismo en Colombia desde la óptica de la acumulación primitiva. Para el efecto, hago un análisis de tres casos concretos: el Bajo Atrato en Chocó, Mapiripán en Meta y Las Pavas en el sur de Bolívar, todos en Colombia, en los que se han presentado hechos de violencia que incluyen desplazamiento forzado y despojo de tierras, con subsecuentes proyectos de cultivo de palma de aceite a gran escala. La discusión trae a colación el mercado internacional de agrocombustibles y la necesidad del Estado colombiano de copar territorios que antes le resultaban hostiles.

Palabras clave: acumulación, acaparamiento, biocombustibles, desplazamiento, conflicto.

\section{Abstract:}

In this paper I examine the connections between the hogging of lands, the oil palm tree cultivations, and the para-militarism in Colombia through the lens of the primitive accumulation. To do so, I analyze three concrete cases: the Bajo Atrato en Chocó [a river basin], Mapiripán in Meta Province, and Las Pavas in the South Bolívar Province. These three Colombian locations have undergone violent events including forced displacement and land deprivation, with subsequent projects for growing oil palm trees on a broad scale. The discussion brings into contention the agricultural biofuel international market and the need by the Colombian State to take some territories that were previously hostile.

Keywords: accumulation, hogging, biofuels, displacement, conflict.

\section{El concepto de acumulación primitiva}

Según Marx (1867), la acumulación presupone excedentes apropiados por las clases dominantes, cuya supervivencia depende de un sistema capitalista en el que los productores de mercancías previamente se han apropiado del capital y el trabajo. El origen del modelo debe explicarse en su punto de partida, cuando la violencia fue decisiva. La apropiación fue así precedida por la conquista, el robo y la esclavitud.

Durante épocas feudales, los campesinos usaban las tierras comunes para alimentar a su ganado. Este statu quo fue interrumpido por la revolución capitalista llevada a cabo a fines del siglo XV, cuando los nuevos proletarios fueron liberados de sus señores feudales debido a las confrontaciones con una nueva nobleza cuyo poder giraba alrededor del dinero. Los robos de tierras estatales fueron ampliamente practicados por los capitalistas, quienes previeron un comercio inmobiliario rentable y la expansión de la agricultura moderna basada en modelos a gran escala. Más tarde, durante el siglo XVIII, se crearon las condiciones para legalizar el robo de las tierras. Mediante numerosos decretos los capitalistas obtuvieron la propiedad de antiguas tierras comunales, convirtiendo a sus habitantes originales en una masa que debía trabajar para ellos (Marx, 1867).

Moore (2004) resume los elementos de la acumulación primitiva de esta manera:

Notas de autor

${ }^{a}$ Autor de correspondencia. Correo electrónico: germantorresmora@gmail.com 
Los métodos por los que la burguesía emergente acumula su primer capital se presentan en un contexto en el que un modo de producción está a punto de perecer. El proletariado agrario y libre es creado por medio del quiebre de los lazos entre los campesinos y la tierra. El capital previamente acumulado se utiliza para levantar los medios de producción que los nuevos proletarios han de utilizar con el fin de producir excedentes a cambio de un salario. La conversión de los derechos colectivos sobre la tierra en propiedad privada, monetariamente transferible.

Vale la pena aclarar que la acumulación primitiva no es lo mismo que la simple acumulación. Ambas tienen en común el hecho de separar a los trabajadores de los medios de producción, pero la primera tiene una condición histórica que la hace anterior a toda acumulación, mientras que la última tiene un matiz continuo de reproducción del capital (De Angelis, 2000). Sin embargo, el carácter histórico de la acumulación primitiva no debe asumirse como una época acabada, sino como un proceso cíclico propio de la reproducción capitalista, que tiene lugar incluso en escenarios de capitalismo maduro (Ulas, 2017). Por ejemplo, la acumulación primitiva puede verse vigente en la expulsión de los trabajadores de los campos para imponer formas privatizadas de control sobre los recursos naturales (Glassman, 2006).

Según Harvey (2010), la acumulación primitiva es un proceso continuo. Existe una conexión entre los métodos de acumulación y explotación, por ejemplo, mediante la privatización de las tierras públicas. Algunos ejemplos ocurren en la China contemporánea, donde el antiguo pueblo agrario se ha convertido en una población urbana de bajos salarios, y en algunas zonas de África, América Latina y el sureste asiático, donde la extracción de recursos naturales conduce a una expropiación violenta de los campesinos.

\section{Acaparamiento de tierras}

El acaparamiento de tierras implica una cantidad considerable de adquisiciones de estas a gran escala con fines comerciales o industriales, por ejemplo, para la producción agrícola y de biocombustibles, la minería o el desarrollo de infraestructura (Gilbert, 2017). Este fenómeno a menudo implica un compromiso de los gobiernos extranjeros en las adquisiciones y un impacto negativo en la seguridad alimentaria de los países donde se hallan las tierras (Borras et al., 2012).

El acaparamiento es justificado, muchas veces, bajo la promesa de modernizar la producción agrícola de alimentos y combustibles en términos industriales (White, 2012). Parece existir un consenso en torno a la disponibilidad de tierra en los países del sur global y la viabilidad de su venta a inversionistas extranjeros. Se da por sentado que debe privilegiarse la atracción de capitales extranjeros por encima de la tierra misma, que se considera subutilizada (Matondi et al., 2011). También existe una tendencia a asumir que este tipo de inversiones crea nuevos empleos, tanto agrícolas como no agrícolas; incrementa el ingreso familiar a través de la figura de cultivo por contrato; facilita la transferencia de tecnologías; aumenta la capacidad de producción de alimentos; y mejora la infraestructura y el acceso a servicios básicos y abre nuevas posibilidades en los mercados internacionales (Franco, 2012).

Algunos hechos que explican este fenómeno, según Sassen (2010), son la demanda global de alimentos y el ascenso de la clase media en Asia, que ha movilizado ganancias a partir de inversiones en tierras, así como la demanda creciente de metales y minerales debido al desarrollo del sector de la electrónica, y el aumento de la demanda de agua y un agotamiento de esta en algunos lugares del mundo.

\section{Tendencias del acaparamiento de tierras}

Algunas tendencias del acaparamiento de tierras incluyen la compra o arrendamientos a largo plazo para la producción de alimentos, lo mismo que una fuerte participación de China, Corea del Sur, Japón y los estados del Golfo para garantizar su seguridad alimentaria, teniendo en cuenta los rápidos cambios en el crecimiento 
económico de las dietas y las limitadas tierras de cultivo de que disponen, hechos que los han convertido en importadores de productos agrícolas (Seo y Rodríguez, 2012). Merece también mencionarse que en muchas ocasiones las inversiones son efectuadas por empresas holding, no siempre expertas en producción de alimentos, y frecuentemente financiadas por los gobiernos de sus países (Hallam, 2009).

El acaparamiento actual implica inversiones en tierras agrícolas en países ubicados en el sur global para garantizar la producción de alimentos. Además, los gobiernos de estos países a menudo están interesados en atraer inversiones extranjeras para explotar sus tierras (Hallam, 2009; Seo y Rodríguez, 2012).

Existe un cambio en el acceso a la tierra, lo mismo que en el control y en la propiedad de la misma. El proceso actual se caracteriza por negociaciones rápidas y secretas suscritas entre los gobiernos anfitriones y los inversionistas foráneos, por lo general excluyendo a los propietarios locales y a las comunidades (White, 2012). Al final, se concluyen contratos vinculantes que, aunque legales por completo, resultan asimétricos, teniendo en cuenta los riesgos que se toman y el acceso limitado a la información, concretamente entre las partes más débiles de la relación. En los países localizados en el sur global no hay lineamientos adecuados que regulen la transferencia de tierras, y los inversionistas se aprovechan de estos vacíos (Matondi et al., 2011).

Finalmente, debe destacarse que el acaparamiento de tierras contemporáneo está inmerso en diferentes crisis, como las de la energía, las finanzas, los alimentos, el combustible y el calentamiento global. Teniendo esto en cuenta, se prefieren aquellos productos fácilmente intercambiables y con un cierto grado de flexibilidad. Por ejemplo, la soya es útil no solo como alimento sino también como material de alimentación y biodiesel; la caña de azúcar y el maíz son útiles como alimento y como etanol, y el aceite de palma puede usarse como alimento, biodiesel o para aplicaciones industriales (Borras et al., 2012).

\section{La importancia de la palma de aceite}

El análisis del acaparamiento de tierras contemporáneo requiere incluir el estudio de la palma africana. La demanda de aceite de palma ha incrementado a nivel mundial debido a que es una fuente no emisora de carbón y puede remplazar a los combustibles fósiles. Se espera que para 2030 el consumo de energía se incremente en un $60 \%$, por lo que la diversificación en la producción parece un negocio rentable. Colombia no ha sido ajena a esta dinámica, y por eso ha hecho un esfuerzo notable para entrar en el negocio, al convertirse en el cuarto productor de palma aceitera en el mundo, solo por detrás de Indonesia, India y Malasia (Maughan, 2011).

El acaparamiento de tierras es una respuesta a la inseguridad y vulnerabilidad generada por la expansión comercial de los agrocombustibles y sistemas financieros (Matondi et al., 2011). Luego del boom global de los commodities y de la crisis de 2008, las inversiones en cultivos de palma crecieron, frecuentemente por el impulso de firmas capitalistas regionales vinculadas a cadenas de commodities, que a su vez son dominadas por poderosas corporaciones globales (Gellert, 2015).

Los procesos de adquisición de grandes extensiones de tierras para el cultivo de palma han sido descritos como acaparamiento de tierra (Bissonnette, 2013). En Colombia, por ejemplo, se ha verificado que, a pesar del incremento notable de la producción de aceite de palma, el número de plantas procesadoras ha permanecido estable: entre 1999 y 2010 la capacidad de procesamiento incrementó de 746 a 1249 toneladas por hora, mientras que las plantas de procesamiento apenas variaron de 51 a 54 . Esta tendencia solo puede explicarse por el aumento del área de cultivo y mejoras en la capacidad de las plantas de procesamiento (Marín-Burgos y Clancy, 2017).

\section{Acumulación primitiva y acaparamiento de tierras}

La acumulación primitiva descrita es básicamente la destrucción de varias formas sociales a través de la coerción extraeconómica y la violencia extralegal, con el fin de uniformar las relaciones capitalistas entre la 
mano de obra y la propiedad privada, formando flujos de personas, commodities y saberes que se entrelazan en el proceso de acumulación. Esta articulación permite comprender los cambios de agricultura de subsistencia a agricultura capitalista, por ejemplo, mediante el tránsito de la producción de productos primarios a economías exportadoras en las que los pequeños productores operan por medio de cadenas de valor; o, en otras palabras, a través de nuevas relaciones sociales con patrones específicos de acumulación, proceso que lleva a una rápida proletarización del productor independiente (Ulas, 2014).

La acumulación primitiva en estos escenarios no opera enteramente a través de la desposesión de la tierra, sino de la capitalización de las relaciones sociales de producción de la agricultura, que son abandonadas a la suerte de los imperativos del mercado. Este proceso no implica coerción, pero sí hay otras maniobras institucionales: impuestos, inducción a la deuda y varios esquemas de reforma agraria que promueven la formación de una masa menos campesina y más proletaria (Ulas, 2014; Moyo et al., 2012). Moore (2004) va un poco más lejos, al afirmar que el desarrollo va necesariamente aparejado a la acumulación primitiva. Lo propio hace Glassman (2006), para indicar que se trata de un fenómeno cuya importancia no se reduce al sur global, sino que hace parte de la formación del norte global; la acumulación primitiva debe ser vista como consustancial al desarrollo en cualquier parte del mundo.

La adquisición de tierras en los países del sur global no es, a pesar de todo, un fenómeno nuevo; así lo han hecho las potencias coloniales en el pasado. Sin embargo, los mecanismos actuales involucran, no un imperio en expansión, sino al menos dos Estados nacionales reconocidos como soberanos. En este caso no se trata de un acaparamiento imperialista sino de una inversión extranjera perfectamente planeada (Sassen, 2010).

A diferencia de lo que ocurría en eras coloniales, este tiempo de biocombustibles supone menos el uso de las armas; la lucha se sitúa más en las oficinas corporativas y los mercados internacionales. A su vez, mientras en épocas pretéritas el colonialismo promovió ampliamente el asentamiento de poblaciones occidentales, hoy en día los países e inversionistas interesados en adquirir tierras parecen más decididos a establecer modelos de agricultura a gran escala (Matondi et al., 2011).

\section{Desplazamiento forzado, desposesión y acumulación primitiva en Colombia}

A diferencia de otros casos en la región latinoamericana, el acaparamiento de tierras en Colombia ha sido fuertemente determinado por el conflicto armado, que ha dejado como saldo más de 5,1 millones de personas desplazadas y 6,6 millones de hectáreas despojadas (Salinas, 2012). El conflicto armado colombiano es problemático cuando se trata de acaparamiento de tierras, pues los grupos armados, principalmente guerrilleros y paramilitares, no son los únicos actores. El desplazamiento también puede deberse a la acción de ganaderos, narcotraficantes, especuladores de tierras, autoridades institucionales y empresas nacionales e internacionales (Gómez et al., 2015). Este proceso de expulsión violenta de los campesinos, curiosamente, ha sido capaz de estimular el desarrollo económico, por ejemplo, desplazando a los pequeños propietarios, cuyos márgenes de rentabilidad distan de los de la agroindustria, que toma el lugar dejado por aquellos (Gómez et al., 2015).

El despojo de tierras ha abierto los campos a grandes inversiones, transformando extensos lugares una vez dominados por la agricultura a pequeña escala, creando un espacio donde se llevan a cabo ambiciosos proyectos agroindustriales. Un ejemplo bien documentado es el valle del Bajo Atrato, donde los cultivos de palma aceitera tuvieron éxito después de que los paramilitares tomaron el control del lugar. Situaciones similares ocurrieron en el departamento de Meta, donde las empresas aprovecharon situaciones que incluyeron el desplazamiento forzado y el asesinato de líderes sindicales que reclamaban mejoras laborales. También en Montes de María, donde se llevaron a cabo grandes proyectos en tierras abandonadas (Cramer y Wood, 2017). 
Esta asociación entre la palma aceitera y el desplazamiento forzado ha sido estudiada más a fondo por Rey Sabogal (2013), quien encontró que los municipios donde esta se cultiva han tenido más probabilidades de expulsar a la población. De hecho, solo el 8,2\% de los municipios de Colombia cultivan palma de aceite, pero son el escenario del $22,4 \%$ del desplazamiento forzado total. Por su parte, mientras aquellos municipios en donde no hay palma aceitera tienen tasas de expulsión de 97 personas por cada mil habitantes, los que tienen palma expulsaron a una tasa de 181 personas por cada mil habitantes. El estudio encontró una correlación positiva para las variables palma de aceite y desplazamiento forzado, incluso si el cultivo es reciente, como ocurre en el Meta (Rey Sabogal, 2013).

Según Baquero (2017), el desplazamiento forzado en algunas regiones del país, entre ellas el Bajo Atrato, está conectado con la dinámica de expansión de las materias primas que sirven para la producción de agrocombustibles, particularmente entre 2002 y 2008, periodo en el que se registra una expansión del cultivo de palma gracias al favorecimiento del gobierno de turno. Por su parte, Marín-Burgos y Clancy (2017) sostienen que la palma de aceite no solo ha hecho uso de esquemas asociativos con los campesinos, sino que eventualmente se ha valido de estrategias de acumulación para tomar el control sobre la tierra, que incluyen desplazamiento forzado, utilización de tierras abandonadas por causa del conflicto, utilización de tierras con derechos de propiedad en entredicho, y ocupación de tierras públicas.

\section{Cultivo de palma aceitera}

La palma aceitera es un cultivo tropical y perenne, cuyo ciclo productivo puede durar hasta 50 años, pero que con fines comerciales se cultiva hasta 25 años, debido a las desventajas de las alturas que se alcanzan por encima de esa edad, especialmente en las actividades de corte del fruto. Su cultivo en Colombia comenzó en 1945, por parte de la United Fruit Company (Aguilera Díaz, 2002). Su despegue comercial, sin embargo, no ocurrió hasta 1960, y se ha expandido continuamente, con crecimientos que han dependido del apoyo del gobierno de turno, cambios en el mercado y condiciones agroecológicas. El crecimiento fue particularmente notable entre 1960 y 1990, debido a políticas proteccionistas para controlar la importación de aceites vegetales, lo que hizo más competitivo el precio de la palma local y, en consecuencia, facilitó el despegue del sector palmero nacional. Posteriormente, en los noventa, la liberalización y la apertura económica, hicieron difícil la competencia para los productores nacionales (Marín-Burgos y Clancy, 2017).

La producción de palma de aceite se vio nuevamente favorecida a partir del año 2002, cuando el gobierno de Uribe Vélez la benefició a través de exenciones de impuestos, facilidades de crédito, subsidios, incentivos fiscales y regulación de precios. La situación local se complementó con un favorable panorama internacional debido al incremento del uso de aceites vegetales para la producción de biodiesel a nivel mundial, especialmente en la Unión Europea (Marín-Burgos y Clancy, 2017).

El cultivo de palma en Colombia ha aumentado progresivamente desde los años sesenta, cuando las plantaciones cubrían 18.000 hectáreas (Mujica, 2010). En 2015, los cultivos cubrían 664.337 hectáreas y, según estimaciones, en 2020 ocuparán 996.296 hectáreas. Su producción ha sido ampliamente fomentada, inicialmente para la producción de aceite de cocina, y desde la última década para la producción de biodiesel (Salinas, 2012). Actualmente hay 6 plantas de biodiesel, que procesan 546.000 toneladas de frutos por año (Delgado et al., 2015). Aun así, Colombia está lejos de los niveles de producción de Indonesia, el principal productor mundial de palma de aceite, donde 10 millones de hectáreas de bosque han sido convertidas a este monocultivo por parte de empresarios privados (Gellert, 2015). Colombia, sin embargo, tiene 5 veces más tierras disponibles para este cultivo que Indonesia (Delgado et al., 2015).

Según Ballvé (2012), el proceso de acumulación primitiva hace parte de la producción del Estado colombiano. A pesar de la ilegalidad de las operaciones paramilitares, estas han reconfigurado territorialmente algunas regiones, proyectando la presencia estatal a través de la construcción de infraestructura, 
burocracia, agronegocios, organizaciones no gubernamentales y servicios públicos. Los paramilitares pueden desestabilizar algunas instituciones del Estado, pero facilitan su territorialización e incluso asumen algunas de sus funciones (Ballvé, 2012)

Las prácticas territoriales de los paramilitares para la promoción del desarrollo han incluido la siembra de palma de aceite, que muchas veces ha contado con financiación del Estado y de la cooperación internacional. Particularmente, en la región del río Curvaradó los paramilitares implementaron proyectos de palma a gran escala, para lo que acapararon alrededor de unas 22.000 hectáreas de tierras pertenecientes a grupos afrocolombianos (Ballvé, 2012). Según Grajales (2016), estas plantaciones sirvieron, además, a los grupos contrainsurgentes para blanquear capitales, asegurarse una base económica y compensar con una parcela a sus miembros, garantizando así presencia en el territorio. Estas plantaciones solo fueron posibles mediante la articulación de capitales legales e ilegales y la aquiescencia del gobierno, en un proceso que llevó no solo al desplazamiento de campesinos sino también a la llegada del Estado, por ejemplo, mediante la instalación de bases militares cercanas a los cultivos. Este desplazamiento masivo y la producción de territorio demuestran qué tan primitiva es esta acumulación, sobre todo ante la evidencia de la violencia que puede implicar el desarrollo capitalista y las relaciones sociales propias de la formación del Estado (Ballvé, 2012).

Según Mignorance et al. (2004), a parte de los beneficios económicos de la palma de aceite y de la concentración de la tierra en manos de personas ajenas a las comunidades donde esta se siembra, existen otros propósitos y beneficios bien esclarecidos que se han asociado a este cultivo. Entre estos se cuentan la colonización agraria, cambios en la estructura de la tierra, el control militar, social y político de los lugares de expansión, y la lucha contra la guerrilla. Particularmente, los paramilitares han mantenido la seguridad de estas zonas, recibiendo a cambio notables compensaciones económicas. Hay un vínculo entre el cultivo de la palma de aceite y el conflicto armado, que se verifica en zonas donde compañías palmeras han sembrado luego de que las comunidades originalmente establecidas han sido forzadas a abandonar o les han despojado las tierras, situación que se agrava por la informalidad en la tenencia, el tráfico de droga y el lavado de dinero (Seeboldt y Salinas, 2010).

Por su parte, Goebertus (2008) afirma que en el municipio Zona Bananera en Magdalena, la palma de aceite ha incidido en el desplazamiento forzado. Debido a la falta de presencia estatal, los grupos de contrainsurgencia se aliaron estratégicamente con los grupos productores de banano y palma para lograr una inserción estratégica en el lugar, haciendo uso de la extorsión y el desplazamiento.

En aras del desarrollo del país, se ha promovido ampliamente la expansión de la frontera agrícola, sobre todo a través de cultivos de palma de aceite, que muchas veces se han servido de estrategias legales e ilegales para acaparar tierras (Piñeros, 2016). En Colombia, el desplazamiento forzado no es una mera consecuencia del conflicto armado, sino que ha sido un fin intencionalmente perseguido por parte de los actores del mismo, de cara a promover proyectos de desarrollo (Thomson, 2011).

\section{Introducción a la violencia paramilitar en Colombia}

Los hechos de violencia en Colombia han sido vitales en la historia política del país y en la definición de las relaciones en torno a la propiedad y control de la tierra. Ha sido de especial relevancia el accionar de los grupos paramilitares creados con el fin de combatir a los grupos insurgentes. Dichos grupos han desplegado diversas actividades que incluyen la violencia y la participación en política (Grajales, 2011), dejando como saldo hechos de migración forzada que reconfiguran los escenarios locales. La tierra, que muchas veces ha sido despojada, es utilizada para controlar amplias regiones del país, mediante la implantación en ella de bases sociales que simpatizan con la causa contrainsurgente, y por medio de su entrega a políticos aliados. Al final de este proceso se destaca, además, la apertura de grandes extensiones de tierra para el establecimiento de 
proyectos agroindustriales y, con ello, la transformación del uso del suelo según lógicas de acumulación de capital (Gómez et al., 2015).

Los grupos paramilitares se han dedicado a proteger la propiedad de sus aliados en contra de la posible amenaza de campesinos sin tierra. Incluso han acumulado tierras por medio del uso de la violencia y la corrupción, no solo a través de mecanismos ilegales, sino también al apoyarse en el aparato estatal, que favoreció el proceso de legalización de lo que violentamente despojaron. Así las cosas, los paramilitares se han comportado de manera dual. Por un lado, han utilizado su capital de violencia, que incluye varias violaciones a derechos humanos, entre ellos el desplazamiento forzado, y su capital social, que incluye la utilización de políticos elegidos popularmente y funcionarios públicos.

El conflicto armado colombiano contemporáneo reúne las condiciones para ser denominado como un proceso de acumulación primitiva. Amplias extensiones de tierras, en un país en el que el 52,2\% de estas carecen de títulos de propiedad (Perfetti y Saavedra, 2017), son arrebatadas de manera violenta con fines de acumulación de capital. El proceso ha sido activamente promovido por diversos grupos a través del uso de la violencia o la amenaza del uso de esta, con el fin de provocar una migración forzada y así privar al enemigo de las bases sociales previamente existentes. Los grupos paramilitares han controlado la tierra a través de diversas estrategias. Primera: mediante la expulsión de civiles en las zonas dominadas por la guerrilla, facilitando la migración de otros campesinos que les guardaban simpatía. Segunda: a través de estructuras clientelistas por las que transferían tierras a sus aliados y élites locales como compensación por sus servicios. Tercera, la más básica, por medio de la apropiación de las tierras arrebatadas para engrosar el patrimonio de los líderes paramilitares (Gómez et al., 2015).

A pesar de la ilegalidad de las acciones ejecutadas por los grupos armados ilegales, estas apuntan a la consolidación de grandes extensiones de tierra que son utilizadas para la edificación de empresas completamente legales, dedicadas a negocios agroindustriales. Este es el punto crucial de la acumulación primitiva, es decir, no solamente el uso de la violencia para hacerse a las tierras, sino la reorientación de estas para el establecimiento de empresas muy rentables. Es de esperarse, entonces, que se presenten transformaciones en el uso del suelo y en el tipo de cultivos, por ejemplo, cambiando sembrados de yuca y plátano, que generalmente se dan en pequeñas propiedades, por cultivos de caña de azúcar y palma de aceite, que tienden a ser cultivos de gran escala (Gómez et al., 2015).

La particularidad del caso colombiano estriba en la capacidad que han exhibido los grupos paramilitares para hacerse al control de grandes extensiones de tierra mediante el uso de la violencia, privando a muchos campesinos de sus derechos sobre aquellas, generalmente vulnerables debido a la inseguridad jurídica. Este no es un fenómeno aislado, sino que responde a lógicas internas de ejercicio del poder a través del control del territorio y de lógicas internacionales de acumulación de capital, que demandan la transformación del uso del suelo con el fin de incrementar la producción de materias primas flexibles, ampliamente demandadas en los mercados internacionales. A continuación, se estudian tres casos que reúnen los elementos de acumulación primitiva, acaparamiento de tierras y el cultivo de la palma de aceite.

\section{El Bajo Atrato chocoano}

Se trata de una subregión conformada por los municipios de Acandí, Unguía, Belén de Bajirá, Carmen del Darién y Riosucio, localizada en la región de Urabá, al extremo noroccidental de Colombia. Esta zona es el punto más estrecho entre ambos océanos en el país, por lo que es muy apetecida por los grupos armados ilegales que trafican bienes (García, 2014).

Desde los setenta, la zona fue dominada por grupos guerrilleros, que inicialmente establecieron una regulación del mercado sin intervención del Estado, y aprovecharon la posición geográfica para traficar armas 
y coca. Sin embargo, a partir de 1996, los paramilitares se apoderaron de la zona, estableciendo lógicas productivas que suponían el control de la tierra, entre ellas el cultivo de palma de aceite (García, 2014).

El proyecto de palma de aceite en el Bajo Atrato enfrentó una dificultad al estar sobre territorios colectivos de comunidades negras, adquiridos a través de títulos expedidos por el Estado colombiano en cumplimiento de lo mandado en la Ley 70 de 1993 (Gobierno de Colombia, 1993; Grajales, 2011). El primer título colectivo se expidió mediante la Resolución 0286 de 1996 (Gobierno de Colombia, 1996) a favor del Consejo comunitario La Madre, en Riosucio. Los consejos comunitarios de Curvaradó y Jiguamiandó recibieron, con posterioridad, 46.084 y 54.973 hectáreas, respectivamente. Sin embargo, debido a circunstancias de orden público, no se hizo una delimitación técnica de la zona, sino que se llegó a un acuerdo entre las comunidades y el gobierno nacional (Ocampo, 2009).

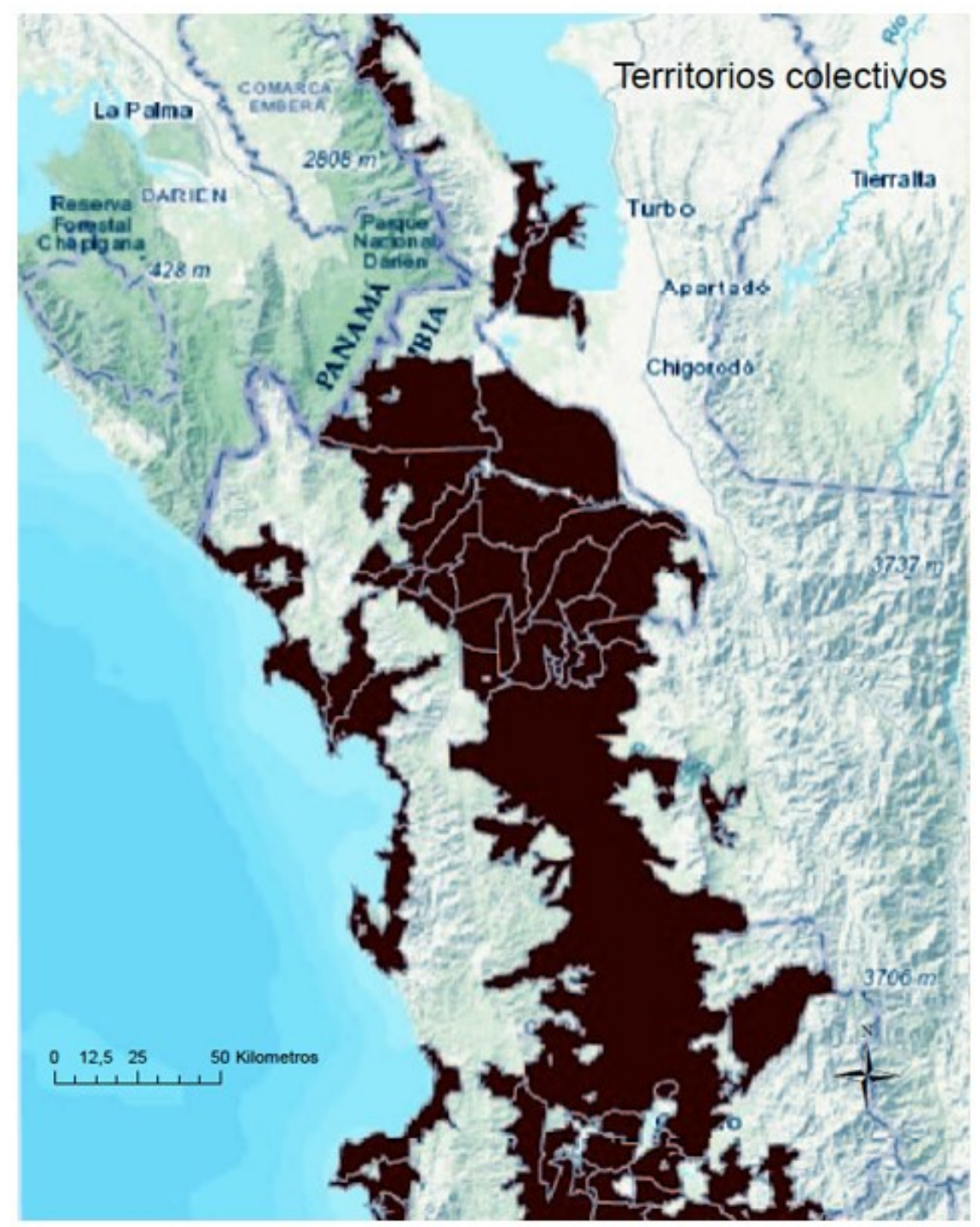

FIGURA 1.

Mapa Territorios colectivos en Chocó

Fuente: elaboración propia con base en el Instituto Geográfico Agustín Codazzi (2018)

El 20 de diciembre de 1996, un grupo de hombres armados identificados como miembros de las Autodefensas Campesinas de Córdoba y Urabá llegaron a Riosucio, para asesinar a un grupo de cinco personas, incluyendo al alcalde, luego de acusarlos de ser colaboradores de la guerrilla. Los ataques continuaron durante los meses siguientes (Grajales, 2011). 
Bien documentado es el caso de la denominada Operación Génesis, una acción adelantada en febrero de 1997 por miembros de la brigada 17 del ejército, que contó con la participación de 12 hombres pertenecientes al bloque Helmer Cárdenas de las Autodefensas, según el decir de Fredy Rendón Herrera, comandante de dicho grupo armado ilegal para la época. La operación tuvo como propósito expulsar al Frente 57 de las FARC (Franco y Restrepo, 2011). Simultáneamente, los paramilitares emprendieron la denominada operación Cacarica, que tenía idéntico propósito. Como resultado, más de 15.000 personas se vieron obligadas a dejar el lugar (Grajales, 2011). Corredor (2015) afirma que estas operaciones armadas, que buscaban perseguir a la guerrilla, también tenían como objetivo expulsar gente de sus territorios, principalmente para instalar cultivos de palma.

Desde 1998 empezó la era de la palma de aceite en el Bajo Atrato, que se plantó en las tierras cuyo abandono fue forzado por la guerra (Defensoría del Pueblo, 2005). Con motivo de la desmovilización del proceso de paz con los grupos paramilitares en el primer gobierno de Álvaro Uribe (2002-2006), estos empezaron a cultivar palma de aceite, para lo cual crearon estrategias de asociación con campesinos aliados, principalmente en la cuenca del Curvaradó, en donde se concentraron hasta el 93\% de los cultivos (Corredor, 2015). Buenos ejemplos son las empresas Urapalma y Asopalma, que se propusieron sembrar alrededor de 20.000 hectáreas y una producción de 35.000 toneladas en cinco años. Naturalmente, la magnitud del negocio demandaba costos de entrada y una proyección a largo plazo, por lo que los promotores tuvieron que apoyarse en recursos técnicos y financieros del Ministerio de Agricultura, la gobernación de Antioquia y el fondo de Fomento para el sector agropecuario, Finagro, entre otros (García, 2014).

El proyecto palmero hizo uso de diversas estrategias para lograr el reconocimiento de la propiedad sobre los predios que habían sido violentamente acaparados, principalmente a través de la cooptación de entidades administradoras de tierras. Las maniobras incluyeron contratos de usufructo; la compraventa de predios privados excluidos de los títulos colectivos; la usurpación de tierras que luego fueron negociadas con quienes tenían derechos sobre ellas (Defensoría del Pueblo, 2005); la falsificación de títulos de compraventa y documentos emitidos presuntamente por los representantes legales del consejo comunitario; la utilización abusiva de la accesión y la compraventa de mejoras al interior del territorio colectivo a personas ajenas a este (Corredor, 2015).

Entre el año 2006 y 2007, el Instituto Colombiano de Desarrollo Rural (Incoder) tramitó un proceso de deslinde de los territorios colectivos Jiguamiandó y Curvaradó, con el fin de verificar cuántos títulos de propiedad existían dentro de ellos. La entidad concluyó que al interior del territorio adjudicado al consejo comunitario del río Curvaradó, 3291 hectáreas eran de carácter privado, mientras que que dentro del consejo comunitario del río Jiguamiandó, 3102 hectáreas ostentaban idéntico carácter. En el proceso el Incoder dejó sin vigencia los títulos falsificados presuntamente expedidos por la misma entidad, aquellos que contenían áreas superiores a las permitidas por la ley, aquellos en los que las extensiones adjudicadas fueron modificadas unilateralmente, por medio de escritura, accesión o englobe, y las compraventas de mejoras en predios de propiedad colectiva que no acreditaron propiedad privada (Instituto Colombiano de Desarrollo Rural, 2012).

La asociación entre el negocio de la palma africana y el desplazamiento forzado fue investigada por la Fiscalía General de la Nación que, en mayo de 2010, ordenó la captura de varios ejecutivos de las firmas Urapalma, Palmas de Curvaradó, Inversiones Agropalma, y Palmas de Bajirá, entre otras (Franco y Restrepo, 2011). Incluso, en una entrevista concedida a la revista Semana, Vicente Castaño reconoció que los paramilitares tenían cultivos de palma en la región y activamente promovieron la entrada de ricos empresarios con el fin de que invirtieran en la zona. Según Castaño, al traer empresarios ricos el Estado también llegaría, pues esa es la única forma en la que las instituciones llegan a ciertos lugares (Grajales, 2011). Por su parte, ante la gravedad del asunto, la Defensoría del pueblo requirió, en el año 2005, a las empresas Urapalma, Palmas de Curvaradó, Palmado Ltda., Palmas S. A., Asibicon, Palmura y Palmas del Atrato que cesaran sus cultivos de palma en los territorios colectivos de Curvaradó y Jiguamiandó (Defensoría del Pueblo, 2005). 
El paramilitarismo asumió una labor de restablecimiento del orden y garantizó el retorno de los empresarios palmeros a la región. Incluso, antiguos comandantes del bloque Elmer Cárdenas declararon que luego de la Operación Génesis y del aseguramiento territorial que esta implicó, Vicente Castaño ordenó la implementación del proyecto palmero en el Bajo Atrato en un proceso escalonado que incluyó la adquisición de las tierras, los arreglos con diversos actores oportunistas y la adecuación de la infraestructura a través de Urapalma, con el fin de atraer otros inversionistas (Franco y Restrepo, 2011).

Los paramilitares apuntaron a recibir el apoyo de los empresarios y terratenientes que previamente habían adquirido tierras a bajo costo, y que a la larga se quedarían con ellas y sus cultivos. Esta estrategia de desarrollo acarreó el desplazamiento de cientos de indígenas y comunidades negras que se negaron a vender sus tierras para el cultivo de palma, y un despojo de unas 22.000 hectáreas. El proyecto palmero, muchas veces presentado como una estrategia para la generación de empresas productivas, ha sido en realidad una apuesta para el repoblamiento y control territorial por parte de los paramilitares (Espinosa, 2012).

Se estima que estos hechos han ocasionado que 110 personas perdieran la vida o hayan sido desaparecidas por parte de la contrainsurgencia ilegal al intentar defender los territorios colectivos de las comunidades negras (Seeboldt y Salinas, 2010). En el año 2001 aún se seguían presentando denuncias por parte de las comunidades de Curvaradó y Jiguamiandó. En estas se relacionaba la expansión del cultivo desde los territorios conocidos como Camelia, Brisitas, La Iguana, La Cristalina, Cetino, La Nevera, No Hay Como Dios, El Firme y Buena Vista, a través de un proyecto que se propuso llegar a cultivar hasta 40.000 hectáreas en estos territorios, sin que exista una clara alinderación para proteger los titulados a las comunidades afrodescendientes. Estas denuncias llegaron a la Corte Interamericana de Derechos Humanos, que en el año 2003 dictó medidas provisionales al Estado colombiano con el fin de que protegiera a las comunidades afectadas, debido a la presencia de grupos armados ilegales en los cultivos (Mignorance et al., 2004).

Según datos del Instituto Geográfico Agustín Codazzi (2018), en el año 2008 aún se registraba producción de palma de aceite en los territorios colectivos afrocolombianos del Chocó, como se ilustra a continuación. 


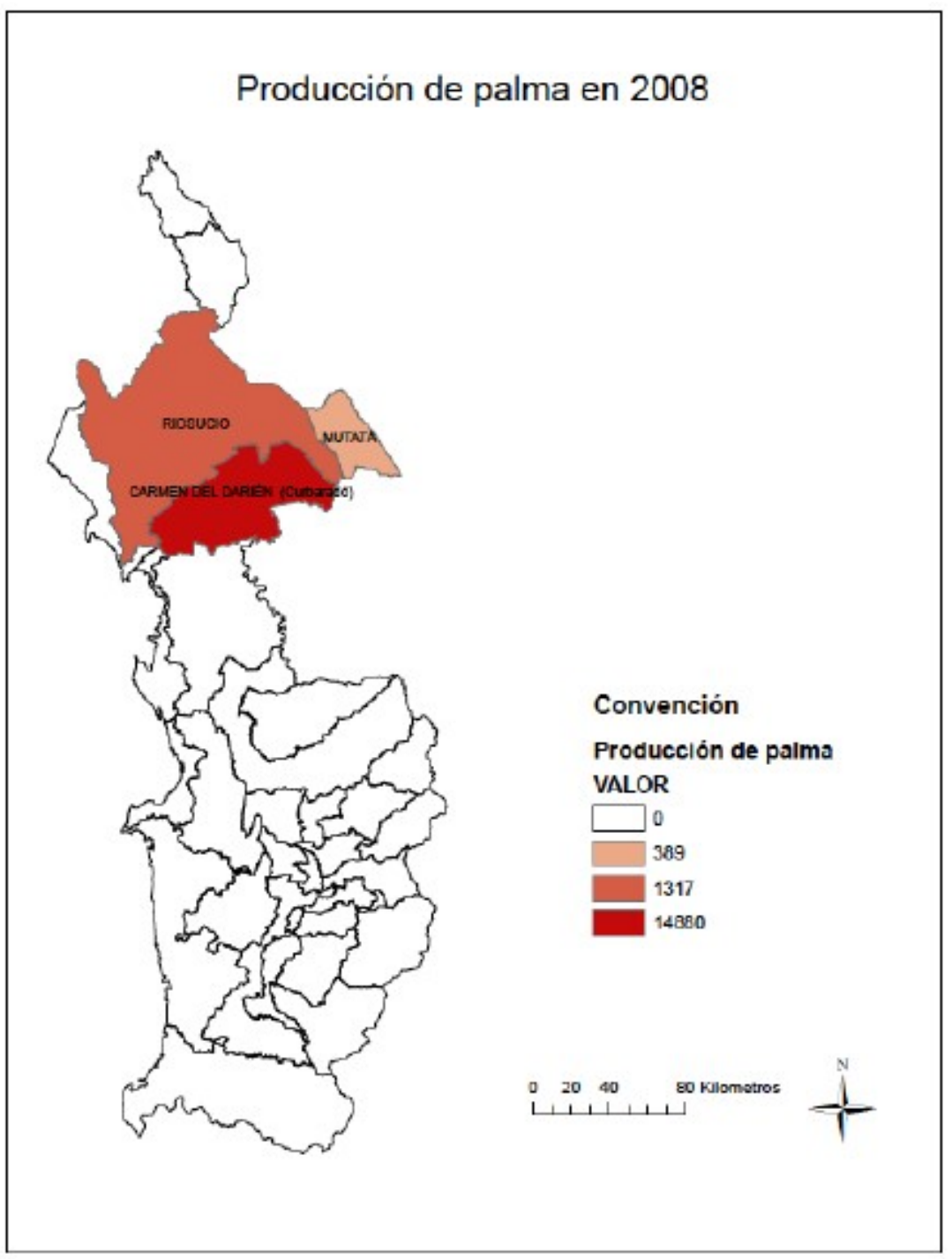

FIGURA 2.

Cultivo de palma de aceite en el año 2008 Nota. Unidad de medida: toneladas por año.

Fuente: elaboración propia con base en el Instituto Geográfico Agustín Codazzi (2018)

Se observa una participación de la producción en los municipios de Riosucio y, sobre todo, Carmen del Darién, en el que se encuentran los consejos comunitarios de Curvaradó y Jiguamiandó. Se incluye también el municipio de Mutatá, por la relevancia geográfica de la expansión del cultivo.

Según Marín-Burgos y Clancy (2017), el caso del Bajo Atrato constituye la forma más extrema del uso de la violencia seguida por cultivos de palma. Los paramilitares usaron una fachada de agronegocios para tener una apariencia de legalidad, ganar control territorial y extraer beneficios económicos. Por su parte, el Instituto Colombiano de Desarrollo Rural (2012) concluyó que, a la par con el desplazamiento forzado de las comunidades ancestrales, todo el territorio colectivo fue afectado por la presencia de diversas empresas palmicultoras, cuyo alcance se extendió hasta las 35.000 hectáreas.

Este caso involucra elementos de violencia en contra de la población civil de los territorios colectivos Jiguamiandó y Curvaradó por parte de estamentos armados institucionales y paramilitares, cuya operación conjunta posibilitó el desplazamiento forzado para así liberar los territorios que estas ocupaban. Esta situación permitió el posterior acaparamiento de territorios étnicos por los grupos paramilitares, que se hicieron a las tierras a través de maniobras legales e ilegales, en articulación con las oficinas administradoras de tierras de la 
región. Una vez asegurados los derechos sobre la tierra, los grupos armados procedieron al cultivo de la palma aceitera y buscaron activamente atraer la inversión en su proyecto de desarrollo. También suplieron varias de las funciones del Estado, principalmente de conservación del orden público. Se observa claramente que la población afrocolombiana fue expulsada a la fuerza de sus territorios colectivos, que progresivamente fueron convertidos en propiedad privada y sirvieron para la expansión de proyectos a gran escala de palma aceitera. A continuación, se relaciona la línea del tiempo correspondiente al caso bajo estudio.

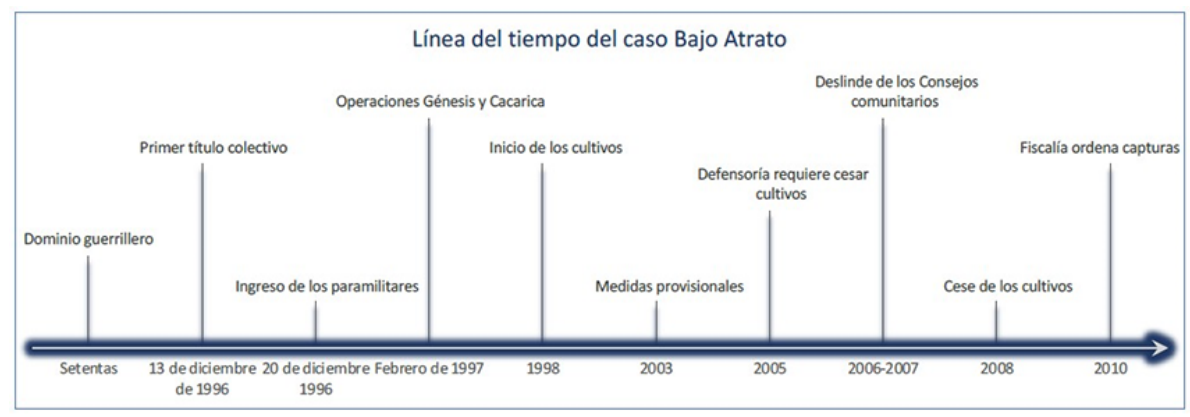

FIGURA 3.

Línea de tiempo. Bajo Atrato

Fuente: elaboración propia

El caso de Macondo se trata de un predio originalmente baldío de 5500 hectáreas, ubicado en Mapiripán, Meta. 


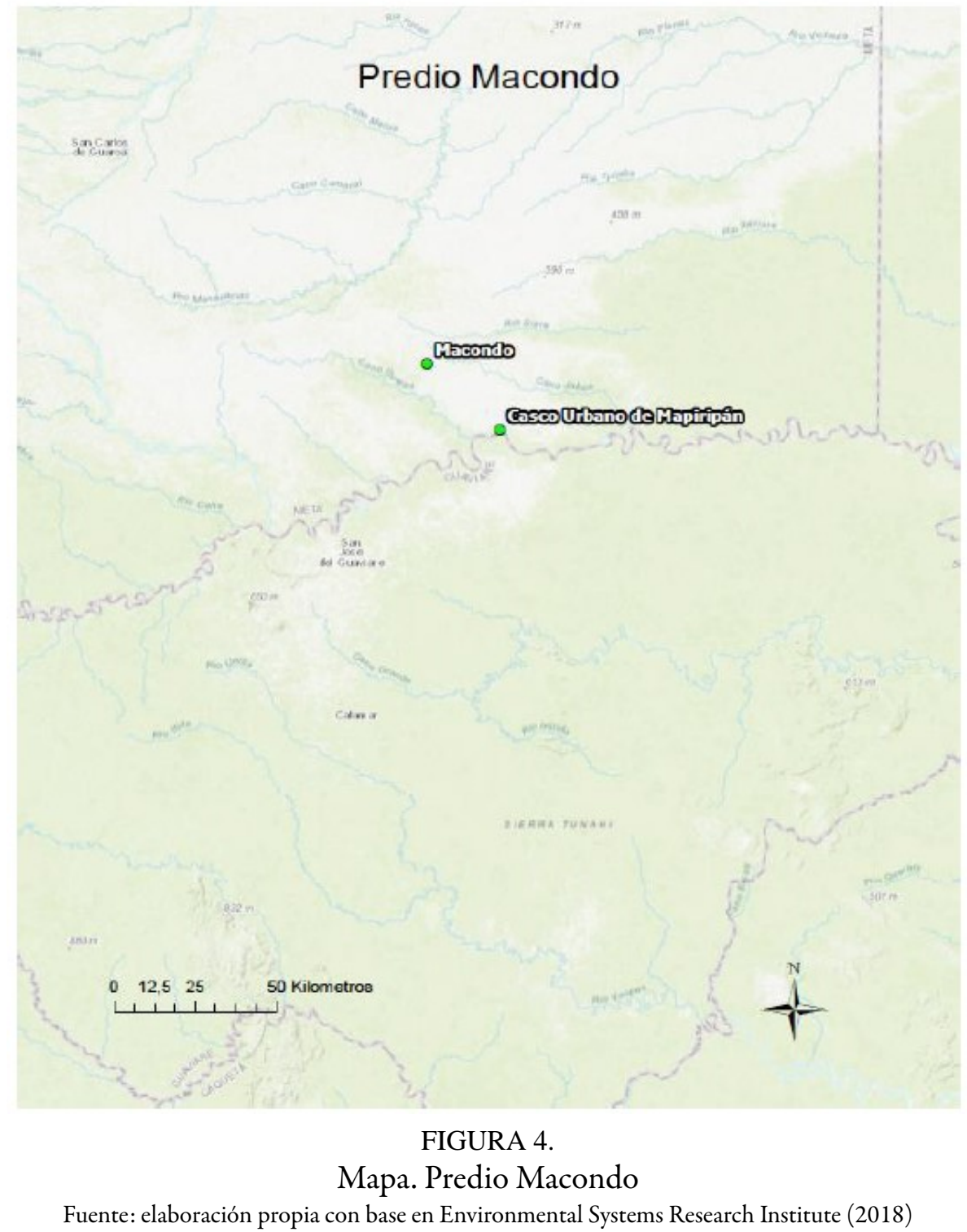

El predio fue originalmente ocupado por una pareja de norteamericanos de apellido Kirby, quienes durante los años cincuenta vieron la llegada constante de colonos desplazados por la violencia. Al parecer, los extranjeros no le encontraron problema alguno al asentamiento de los campesinos. El panorama empezó a cambiar progresivamente durante los años 70 , cuando colonos antioqueños se decidieron a comprarle a los campesinos ocupantes, a pesar de que las tierras no eran fértiles; estaban motivados, más que por el potencial agrícola, por el ganadero. Fue uno de estos colonos antioqueños quien logró que el Estado le adjudicara el predio denominado Macondo (Rodríguez, 2014)

La permanencia de los colonos se vio afectada por la llegada del Frente 44 de las FARC, que controló el lugar desde los noventa, animado por su ubicación para el cultivo y comercio de coca. Sin embargo, en julio de 1997, grupos paramilitares atacaron Mapiripán con la excusa de combatir a las FARC, pero con el objetivo de controlar la producción de cocaína. Durante los años siguientes, 1300 personas fueron desplazadas debido a enfrentamientos armados. Como resultado, el predio Macondo fue abandonado. El desplazamiento fue tan dramático que en 2007 el comité municipal para personas desplazadas ordenó la protección de todas las tierras bajo su jurisdicción, prohibiendo cualquier transacción (Rodríguez, 2014).

Según Finzi (2017), los paramilitares tenían una misión adicional: desarrollar una inmensa plantación de palma de aceite en Mapiripán, con el fin de lavar los dineros mal habidos. A partir de 1999 se registró un 
acaparamiento de tierras y reconfiguración de derechos de propiedad por medios ilícitos, bien sea a través de registros de falsa tradición, declaración de mejoras sobre baldíos, adjudicación de territorios étnicos a quienes no les correspondían y titulación de baldíos a quienes no eran sujetos de reforma agraria de conformidad con la Ley 160 de 1994 (Congreso de Colombia, 1994), en clara connivencia con las entidades administradoras de tierras (Finzi, 2017).

$\mathrm{Al}$ parecer, el predio Macondo fue objeto de una transacción fraudulenta en el año 1999, en la que no participó su propietario. Una parte del predio volvió a cambiar de manos en 2002, hasta que finalmente, fue adquirido en su totalidad en el año 2009 por la empresa Poligrow, que pagó un valor de 4000 millones de pesos luego de haber conseguido el levantamiento de la medida de protección (Rodríguez, 2014). Se trataba de un grupo empresarial de origen italoespañol, formado en Colombia por Poligrow Colombia, Poligrow Agroindustrial, Fundación Poligrow y Electrificadora de Mapiripán S. A. Su principal objeto social es la explotación de aceite de palma y oleaginosas. Según Poligrow, todas las tierras adquiridas fueron terrenos baldíos adjudicados a pequeños productores sin tierra, y las operaciones siguieron las regulaciones colombianas para comprarlas (Salinas et al., 2015).

De acuerdo con el Incoder, Poligrow violó la disposición del artículo 72 de la Ley 160 de 1994 (Congreso de Colombia, 1994), que dispone que no se podrán adquirir predios inicialmente adjudicados como baldíos si los mismos superan la Unidad Agrícola Familiar correspondiente (Finzi, 2017), por lo que la entidad demandó ante la jurisdicción civil la declaración de la nulidad de los contratos correspondientes (Contraloría General de la República, 2014). Poligrow opera hoy en día en otras 5 fincas: El Porvenir, La Cuadra, Las Toninas, Barandeles y Barandales, ocupando hasta 9839,49 hectáreas (Salinas et al., 2015). Según la Contraloría General de la República (2014), la empresa firmó un contrato con el Ministerio de Agricultura y Desarrollo rural para implementar un proyecto de reforestación en la finca Macondo y fue beneficiario de la exención de impuestos para el cultivo de palma aceitera en el predio (Contraloría General de la República, 2014).

La llegada de Poligrow a Mapiripán se dio por la activa promoción del gobierno nacional para atraer inversionistas extranjeros a la altillanura. En el año 2008, la compañía empezó a preparar el predio Macondo, avizorando la difícil situación del suelo, teniendo en cuenta sus altas concentraciones de aluminio y salinidad. Ya para 2014, Poligrow había sembrado 6500 hectáreas de palma, la mayoría de ellas en Macondo. En total el establecimiento de su negocio le costó 29,1 millones de dórales (Salinas et al., 2015).

En el año 2014, la compañía consolidó su primera planta extractora, con capacidad de procesamiento de 7 toneladas de frutos por hora (Salinas et al., 2015), y en el 2018 anunció su ampliación y modernización, de cara a aumentar la capacidad a 45 toneladas de frutos por hora, por lo que se espera un incremento de $7000 \mathrm{a}$ 15.000 hectáreas sembradas con palma. El proyecto requerirá de una inversión superior a los 18 millones de dólares ("Poligrow sembrará", 2017; "Poligrow invertirá", 2018).

De acuerdo con Marín-Burgos y Clancy (2017), este caso parece encajar dentro de una tendencia de concentración ilegal de tierras para el cultivo de palma de aceite en territorios que han sido objeto de procesos de desplazamiento a gran escala y acaparamiento de tierras. Poligrow excedió los límites legales de compra de tierras originalmente baldías medidos en términos de unidades agrícolas familiares, según en el artículo 72 de la Ley 160 de 1994 (Congreso de Colombia, 1994), y contribuyó a agravar los efectos de los procesos de desposesión previos que habían sufrido las víctimas del conflicto armado.

El caso de Macondo hace parte de un proceso mucho más grande que involucra el desplazamiento forzado de un grupo considerable de personas a raíz de enfrentamientos entre grupos paramilitares y de guerrilla. El desplazamiento forzado llevó a que se declarara una medida de protección colectiva que no fue suficiente para evitar que Poligrow adquiriera tierras originalmente baldías, superando los límites legales, diseñados precisamente para evitar la concentración de la tierra. Una vez adquiridos los predios, se iniciaron cultivos de palma aceitera, en un millonario proyecto que sigue funcionando hasta el día de hoy. Se verifica en este caso que no solamente Macondo sino varias veredas del municipio de Mapiripán fueron objeto de violencia y expulsión de los campesinos que allí trabajaban. A su vez, se ha identificado que tierras públicas fueron 
paulatinamente transformadas en propiedad privada a través de procesos de acumulación ilegal, con el objeto de implantar cultivos a gran escala de palma. Abajo se incluye la línea del tiempo de este caso.

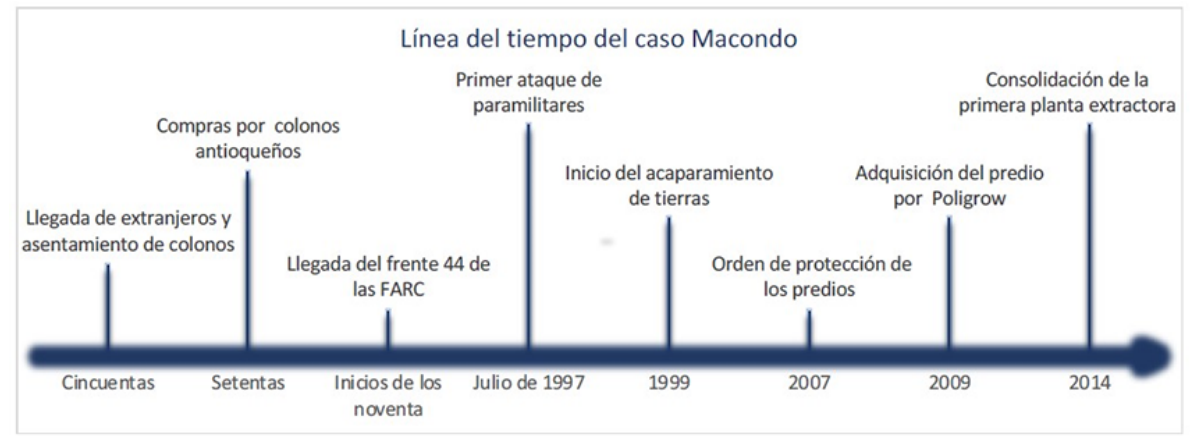

FIGURA 5.

Línea de tiempo. Macondo

Fuente: elaboración propia

El predio conocido como Las Pavas es de unas 2661 hectáreas. Se encuentra entre los municipios El Peñón y San Martín de Loba, en el sur del departamento de Bolívar, en la Costa Norte colombiana (EspinosaManrique y Cuvi, 2016). Desde 1930, el inmueble fue colonizado por campesinos y ganaderos, quienes ocupaban territorios entonces baldíos pertenecientes a la nación (García y Rivera, 2015). Con posterioridad, en 1983, fue adquirido por un narcotraficante, quien lo abandonaría 10 años después debido la persecución del gobierno nacional en contra de su actividad (Espinosa-Manrique y Cuvi, 2016).

En 1995, campesinos provenientes de Buenos Aires, una vereda cercana, aprovecharon que el predio se encontraba vacío y se instalaron allí con el fin de adelantar pequeños proyectos de agricultura. En 2003, grupos paramilitares expulsaron a los campesinos actuando a nombre del propietario original, que puso en venta el predio. En 2005 fue nuevamente ocupado por los campesinos, quienes intentaron negociar con el propietario, luego de haber iniciado un proyecto de cacao. Sin obtener éxito, solicitaron al Incoder que declarara formalmente la extinción del dominio del predio en los términos del artículo 52 de la Ley 160 de 1994 (abandono del predio) (Congreso de Colombia, 1994), y les adjudicara un terreno que ascendía a 1235,5 hectáreas (Censat Agua Viva et al., 2010; Marín-Burgos y Clancy, 2017). 


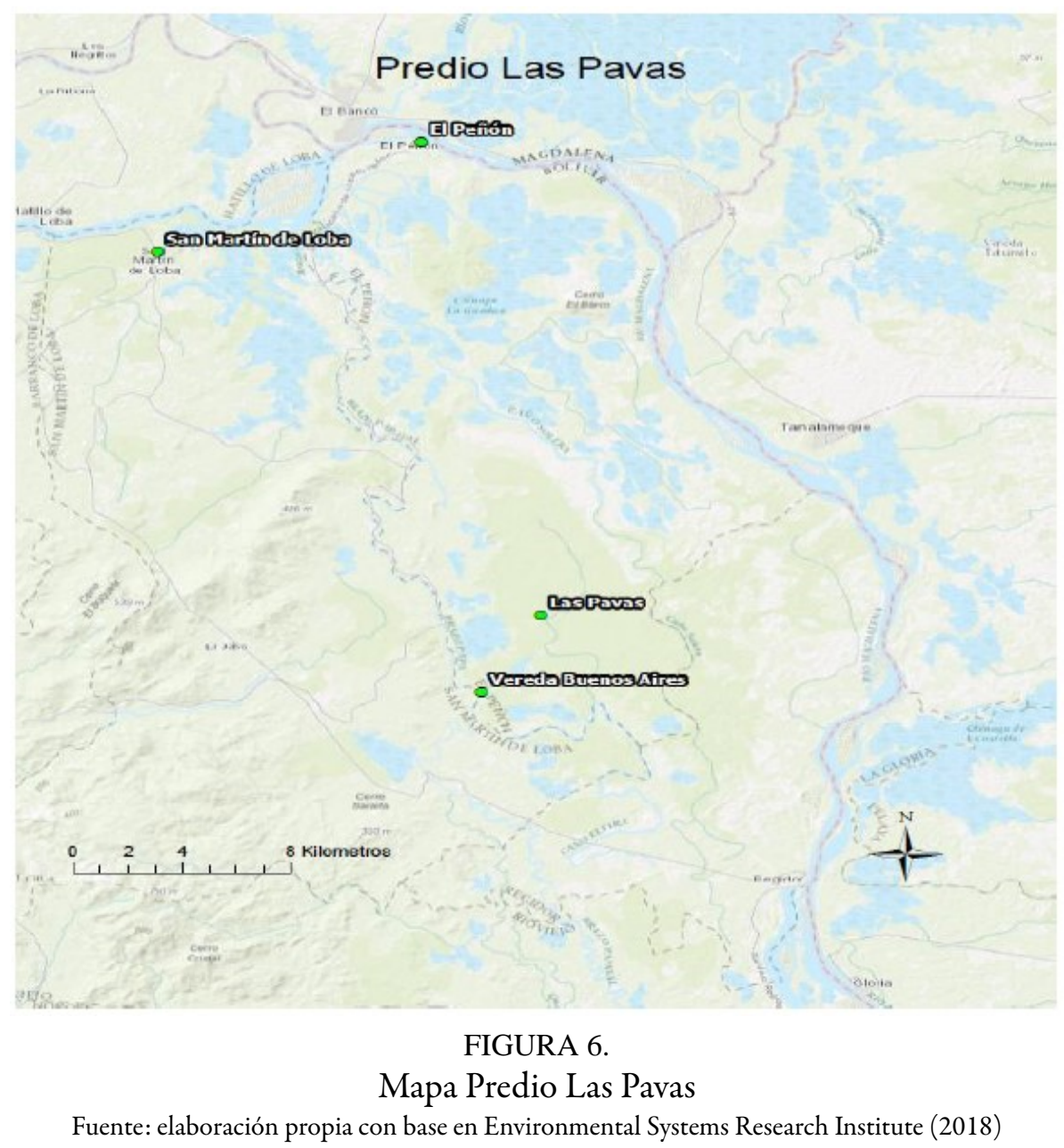

En julio de 2006, hombres armados expulsaron nuevamente a los campesinos. A principios de 2007, el predio fue vendido a la firma Aportes San Isidro en asocio con C. I. Tequendama, una empresa dedicada a la producción de palma de aceite (Gómez et al., 2015), perteneciente al grupo agroindustrial colombiano Daabon Organic, que comercializa aceite de palma y otros productos (Censat Agua Viva et al., 2010).

En el año 2008, las compañías compradoras empezaron a sembrar palma de aceite. Un año después, el predio fue invadido nuevamente por los campesinos. Sin embargo, el consorcio comprador solicitó judicialmente el desalojo de los ocupantes (Hurtado y Pereira, 2011), por lo que estos tuvieron que refugiarse en Buenos Aires, en donde continuaron recibiendo amenazas. En el año 2011, los campesinos retornaron nuevamente, pero se les inició un proceso por los delitos de invasión de tierras y calumnias. Ese mismo año la Corte Constitucional, mediante la Sentencia T-267/2011 (Corte Constitucional de Colombia, 2011) declaró la ilegalidad del desalojo (Espinosa-Manrique y Cuvi, 2016).

En el año 2012, el Instituto Colombiano de Desarrollo Rural (Incoder), al culminar un procedimiento de clarificación de la propiedad, identificó once predios baldíos dentro del predio de mayor extensión Las Pavas, por lo que anunció su recuperación material para titularlo a favor de los campesinos ocupantes. Sin embargo, desde su último retorno estos fueron objeto de varios ataques, entre ellos la destrucción de sus cultivos y ranchos, muerte de sus animales, bloqueo de acceso, quema de cosechas e incluso intentos de homicidio (Espinosa-Manrique y Cuvi, 2016). De acuerdo con Marín-Burgos y Clancy (2017), las compañías palmeras no tuvieron que ver con el desplazamiento, pero sí exacerbaron y profundizaron los procesos de desposesión al apropiarse de tierras públicas sobre las que tenían derechos los campesinos. 
El cultivo de palma de aceite se vio precedido por un proceso de expulsión de los ocupantes por parte de grupos paramilitares que operaban a nombre del propietario original. Este escenario se presentó en tierras privadas, pero también en otras que resultaron ser baldías, luego de la verificación del Incoder. Luego de la expulsión, los inversionistas iniciaron sus cultivos de palma aceitera, para cuya protección acudieron, ante nuevas invasiones, a mecanismos judiciales de derecho civil. No obstante, las decisiones de la Corte constitucional y del Incoder permitieron el retorno de los campesinos ocupantes, que en todo caso no fue pacífico, debido a las amenazas que recibieron. Puede concluirse que hay un proceso de acumulación primitiva observado en la expulsión de los campesinos que ocupaban un predio abandonado, y sobre el que se habían consolidado derechos de propiedad a pesar de estar conformado, al menos en parte, por tierras públicas. El proceso se complementó por la implantación de un proyecto a gran escala de palma de aceite por parte de los inversionistas. A continuación, se incluye la línea del tiempo de este caso.

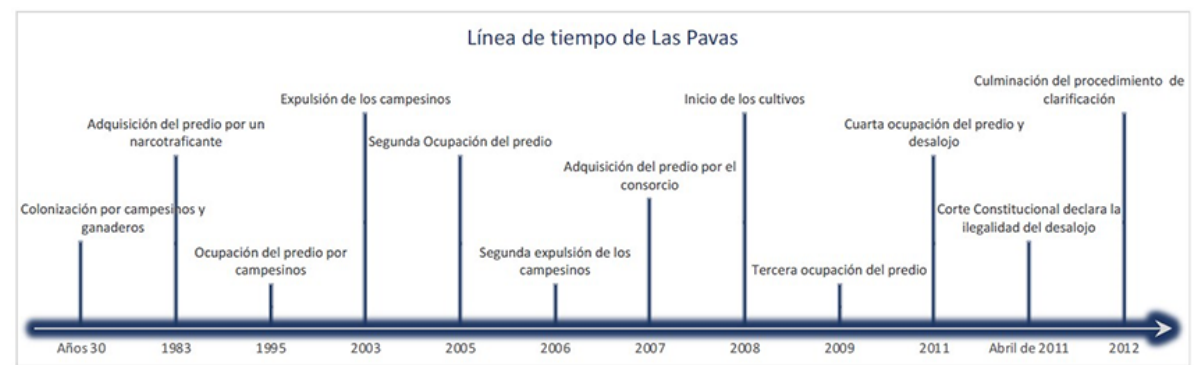

FIGURA 7.

Línea de tiempo. Las Pavas

Fuente: elaboración propia

A continuación, se examinan los elementos que caracterizan cada caso.

TABLA 1

Comparación de escenarios

\begin{tabular}{|c|c|c|c|}
\hline & Bajo Atrato & Poligrow & Las Pavas \\
\hline 1. Contexto & $\begin{array}{l}\text { Zona de dominio guerrillero } \\
\text { durante los setenta, aprovechada } \\
\text { para el tráfico de armas y droga. }\end{array}$ & $\begin{array}{l}\text { Zona dominada por } \\
\text { campesinos durante los setenta } \\
\text { y ganaderos durante los } \\
\text { ochenta. En los noventa la } \\
\text { guerrilla asumió el control del } \\
\text { lugar para la comercialización } \\
\text { de coca. }\end{array}$ & $\begin{array}{l}\text { Predio inicialmente } \\
\text { adquirido para actividades } \\
\text { de narcotráfico en los } \\
\text { ochenta. }\end{array}$ \\
\hline $\begin{array}{l}\text { 2. Escenario } \\
\text { de violencia }\end{array}$ & $\begin{array}{l}\text { Los paramilitares se apoderaron } \\
\text { de la zona desde 1996, cuando } \\
\text { hicieron presencia para } \\
\text { amenazar a los pobladores, a } \\
\text { quienes acusaron de ser } \\
\text { colaboradores de las FARC. El } \\
\text { proceso se completa con la } \\
\text { denominada Operación } \\
\text { Génesis, con colaboración de } \\
\text { guías paramilitares. }\end{array}$ & $\begin{array}{l}\text { Grupos paramilitares se } \\
\text { enfrentaron a la guerrilla en } \\
\text { 1997, choque que dejó } 1300 \\
\text { personas desplazadas. }\end{array}$ & $\begin{array}{l}\text { Grupos paramilitares } \\
\text { expulsaron a los ocupantes } \\
\text { a nombre del propietario } \\
\text { original en } 2003 \text { y } 2006 .\end{array}$ \\
\hline $\begin{array}{l}\text { 3. Naturaleza } \\
\text { de las tierras }\end{array}$ & Étnicas & $\begin{array}{l}\text { Privadas, originalmente } \\
\text { adjudicadas como baldias. }\end{array}$ & $\begin{array}{l}\text { Privadas/baldias por } \\
\text { proceso de clarificación }\end{array}$ \\
\hline $\begin{array}{l}\text { 4. Mecanismos } \\
\text { de } \\
\text { acaparamicnto }\end{array}$ & $\begin{array}{l}\text { Contratos de usuffructo; compraventa } \\
\text { de predios privados excluidos de los } \\
\text { títulos colectivos; usurpación de } \\
\text { ticrras privadas; falsificación de tétulos } \\
\text { de compraventa y documentos } \\
\text { emitidos presuntamente por los } \\
\text { representantes legales del consejo } \\
\text { comunitario; utilización abusiva de la } \\
\text { accesión y la compraventa de mejoras. }\end{array}$ & $\begin{array}{l}\text { Acumulación indebida de } \\
\text { predios originalmente } \\
\text { odjudicados como baldios, } \\
\text { excedicndo la unidad agricola } \\
\text { familiar, en contravención a lo } \\
\text { dispuesto en el articulo } 72 \text { de la } \\
\text { a.cy } 160 \text { de } 1994 .\end{array}$ & $\begin{array}{l}\text { Adquisición de predios } \\
\text { que ostentaban la calidad } \\
\text { de baldios, scgún } \\
\text { procedimiento } \\
\text { administrativo culminado } \\
\text { por el Incoder. }\end{array}$ \\
\hline $\begin{array}{l}\text { 5. Cultivo } \\
\text { subsecuente }\end{array}$ & Palma de accite. & Palma de aceite. & Palma de accite. \\
\hline $\begin{array}{l}\text { 6. Vinculación } \\
\text { de los } \\
\text { paramilitares } \\
\text { con el cultivo }\end{array}$ & $\begin{array}{l}\text { Directa. Los paramilitares eran los } \\
\text { propietarios. }\end{array}$ & $\begin{array}{l}\text { Indirecta. Las operaciones de los } \\
\text { paramilitares permiticron la } \\
\text { entrada de los inversionistas. }\end{array}$ & $\begin{array}{l}\text { Indirecta. Las operaciones } \\
\text { de los paramilitares } \\
\text { permiticron la entrada de } \\
\text { los inversionistas. }\end{array}$ \\
\hline $\begin{array}{l}\text { 7. Origen del } \\
\text { inversionista }\end{array}$ & Nacional. & Internacional. & Nacional. \\
\hline
\end{tabular}

Fuente: elaboración propia 
Tanto en el caso de Bajo Atrato como en el de Poligrow se observa que los territorios inicialmente fueron controlados por grupos guerrilleros, quienes los perdieron a manos de grupos paramilitares. En ambos casos estos aprovecharon escenarios de violencia para arrebatar tierras, y en el caso de Las Pavas amenazaron los ocupantes del bien.

En los tres casos es evidente que los acaparadores pretendieron regularizar el control sobre las tierras a través de mecanismos dispuestos en la legislación colombiana, por ejemplo, a través de compraventas, sin que las mismas fueran, en últimas, la forma adecuada para hacerlo. Se trata de tierras con limitaciones para transferir el derecho de dominio. En el caso de las tierras del Bajo Atrato, por tratarse de tierras de comunidades negras, según las prohibiciones de la Ley 70 de 1993 (Gobierno de Colombia, 1993), que dice que dichas comunidades son inalienables, imprescriptibles e inembargables, situación que impide cualquier acto jurídico comercial sobre las mismas. En el caso de Poligrow y Las Pavas, por haber ostentado u ostentar las tierras la calidad de baldías, de acuerdo con las prohibiciones de la Ley 160 de 1994 (Congreso de Colombia, 1994). Según esta norma, no pueden adquirirse tierras que alguna vez fueron adjudicadas como baldías a través de negocios que exceden la Unidad Agrícola Familiar. Además, las tierras actualmente baldías deben ser adjudicadas a personas de bajos recursos que carezcan de otros inmuebles rurales en el territorio nacional por la autoridad correspondiente — hoy la Agencia Nacional de Tierras, según el Decreto 902 de 2012 (Gobierno de Colombia, 2012) - mandato que excluye cualquier negocio traslaticio de dominio sobre aquellas.

En todos los casos se observa que, luego de arrebatadas las tierras y realizadas las maniobras jurídicas para su regularización, se implementaron cultivos de palma aceitera a gran escala. Esto se hizo a través del control directo del negocio por parte de los grupos paramilitares, como ocurrió en el caso del Bajo Atrato, en donde ellos mismos cultivaron y comercializaron la especie a través de la creación de empresas para el efecto, o facilitando el acceso de inversionistas que adquirieron las tierras con el fin de implementar dicho cultivo, como ocurrió en el caso de Macondo con la italoespañola Poligrow, y en Las Pavas con las firmas colombianas Aportes San Isidro y C. I. Tequendama.

\section{Conclusiones}

La acumulación primitiva es un proceso que se sigue verificando en Colombia, a pesar de que fue pensada inicialmente como una etapa anterior al capitalismo. Esto se debe a que es recurrente en el país la toma violenta de tierras, muchas de ellas públicas o colectivas, en la medida de que se trata de bienes baldíos destinados a reforma agraria o de territorios étnicos que reconocen la ocupación ancestral de comunidades negras. Este proceso se beneficia de una extendida inseguridad jurídica de la tenencia de la tierra y de un contexto de conflicto armado. En el proceso, los campesinos son brutalmente expulsados de sus predios, que una vez regularizados son utilizados para proyectos agroindustriales, fenómeno que responde a la dinámica del mercado internacional.

La acumulación primitiva de los tres casos parece reunir los elementos coercitivos y violentos propios de la definición marxista, verificados por hechos de desplazamiento forzado y despojo, llevados a cabos por grupos paramilitares sobre tierras públicas o colectivas. Estos grupos se han valido del uso de la fuerza o de la amenaza del uso de esta para controlar el territorio, estableciendo bases sociales a través de asignaciones de tierra a favor de campesinos o políticos aliados y/o engrosando ellos mismos su propio patrimonio. Sin embargo, el caso colombiano también reúne elementos agregados en la literatura contemporánea, que incluyen herramientas legales y contractuales, por ejemplo, las compraventas de mejoras, el uso de la accesión, el usufructo y los englobes de tierras, mecanismos que resultan ilegales a la luz de las regulaciones que protegen las tierras destinadas a reforma agraria o que cumplen fines redistributivos a favor de grupos étnicos.

El despojo de tierras cometido por los paramilitares ha permitido el aseguramiento del control territorial del Estado. Aquellos han suplido las funciones de este último en zonas que antes eran controladas por 
grupos insurgentes, principalmente en materia de orden público, pero también a través de la cooptación de funcionarios públicos, por ejemplo, de las oficinas administradoras de tierras, lo que les permitió adquirir la propiedad de estas, aun por medio de mecanismos ilegales, pero con apariencia de legalidad. Una vez asegurado el territorio, se generó un espacio propicio para la atracción de inversionistas, que encontraron a su llegada amplias extensiones de tierras. En su pensar, estas servirían para cultivos mucho más rentables que aquellos usualmente implementados a través de agricultura familiar.

El acaparamiento en Colombia responde a las dinámicas internacionales, en las que la falta de tierra en algunos países, lo mismo que el afán por diversificar las fuentes de energía a través de los biocombustibles, ha promovido la adquisición de grandes extensiones de tierra. Sin embargo, el caso colombiano está ampliamente definido por hechos de conflicto armado, que facilitan la apropiación de territorios y el despojo material de los inmuebles. La acumulación primitiva en Colombia opera como proceso anterior a grandes adquisiciones de tierra por parte de inversionistas locales o foráneos, o incluso por parte de los mismos grupos paramilitares, como ocurrió en el Bajo Atrato. Dichas adquisiciones tienen como fin, al menos en los casos estudiados, implementar proyectos a gran escala de productos flexibles y fácilmente comercializables en el exterior, por ejemplo, caña de azúcar o palma de aceite, objetivo que conlleva a la transformación del uso del suelo, que antes se utilizaba para cultivos de pequeña escala, como la yuca o el plátano.

El desarrollo del campo colombiano en los términos internacionales parece que no es obstaculizado por el conflicto armado; al contrario, al parecer se beneficia del mismo. El incremento de la demanda de biocombustibles hace más atractivos los cultivos que sirven para su producción y, por lo tanto, es de esperarse una expansión de los mismos a través de grandes extensiones, en detrimento de aquellos tradicionalmente sembrados a escala familiar. El contexto de violencia y el accionar de los grupos paramilitares han facilitado las condiciones para la expansión del capitalismo agroindustrial, como quiera que han arrojado de sus tierras a campesinos pobres para luego facilitar el desarrollo de prósperos proyectos de palma africana.

Parece haber una relación entre la palma de aceite y el desplazamiento forzado, que requiere aún una exploración. No se trata de que los inversionistas siempre estén involucrados en acciones delictivas de despojo, pero sí de un aprovechamiento de hechos de violencia previos sobre los inmuebles. En los tres casos estudiados los cultivos de palma se expandieron en zonas en las que se presentaron hechos de violencia y desplazamiento forzado perpetrados por grupos paramilitares. Al menos en el caso del Bajo Atrato se verificó una intencionalidad, como quiera que las empresas que controlaban el negocio fueron creadas por los grupos paramilitares. En los otros dos casos no se puede hablar de la misma intencionalidad, pero sí es evidente que la implementación de los cultivos habría sido imposible sin la expulsión previa de los campesinos. Así las cosas, puede afirmarse que existe cuando hay una relación indirecta entre la acumulación primitiva de tierras públicas o colectivas y la implementación de proyectos a gran escala de cultivos de palma africana, como quiera que los mismos se benefician de las dinámicas propias de la guerra en el caso colombiano. Los paramilitares han cumplido una labor eficaz en la evicción de campesinos dedicados a cultivos poco rentables en los mercados internacionales, para así promover el desarrollo de la palma de aceite, que, en vista de su creciente demanda, resulta mucho más atractiva.

\section{Referencias}

Aguilera Díaz, M. (2002). Palma africana en la costa Caribe. Banco de la República.

Ballvé, T. (2012). Everyday state formation: territory, decentralization, and the narco landgrab in Colombia. Environment and Planning D: Society and Space, 30(1), 603-622.

Baquero, J. (2017). Desigualdades superpuestas, capas de desigualdad e interseccionalidad: consideraciones analíticas y aplicación al caso colombiano. Análisis Político, 89(1), 59-75.

Bissonnette, J. (2013). Processes of land accumulation and patterns of labour mobility in large-scale oil palm smallholding schemes in Indonesia (Documento de trabajo N. ${ }^{\circ} 47$ ). The Land Deal Politics Initiative. 
Borras, S., Franco, J., Gómez, S., Kay, C., y Spoor, M. (2012). Land grabbing in Latin America and the Caribbean. The Journal of Peasant Studies, 39(3-4), 845-872. https://www.doi.org/10.1080/03066150.2012.679931

Censat Agua Viva, CNA, Comisión Intereclesial de Justicia y Paz, Diócesis de Quibdó, Fenacoa, La Vía Campesina Colombia, Fensuagro, Organización Nacional Indígena de Colombia, y Proceso de Comunidades Negras. (2010). Misión internacional para la verificación del impacto de los agrocombustibles en 5 zonas afectadas por los monocultivos de palma aceitera y caña de azúcar en Colombia: impactos sobre los territorios, los derechos, la soberanía alimentaria y el medio ambiente. Fian.

Congreso de Colombia. (1994). Ley 160 de 1994. http://www.secretariasenado.gov.co/senado/basedoc/ley_0160_ 1994.html

Contraloría General de la República. (2014). Informe de actuación especial sobre la acumulación irregular de predios baldios en la altillanura colombiana.

Corredor, J. (2015). La Construcción del Estado a Partir de los Conflictos Territoriales en el Bajo Atrato. Revista de estudos \& pesquisas sobre as Américas, 9(3), 1-21.

Corte Constitucional de Colombia. (2011). Sentencia T-267/2011. https://www.corteconstitucional.gov.co/relator ia/2011/T-267-11.htm

Cramer, C., y Wood, E. (2017). Land rights, restitution, politics, and war in Colombia. Journal of agrarian change, $17(4), 733-738$.

De Angelis, M. (2000). Marx's Theory of Primitive Accumulation: A Suggested Reinterpretation (Documento de trabajo N. . 29). Universidad del Este de Londres.

Defensoría del Pueblo. (2005). Resolución defensorial no. 39. Violación de los derechos humanos por siembra de palma africana en territorios colectivos de Jiguamiandó y Curvaradó - Chocó.

Delgado, J., Salgado, J., y Pérez, R. (2015). Perspectivas de los biocombustibles en Colombia. Revista Ingenierías, 14(27), 13-28.

Environmental Systems Research Institute. (2018). ArcGIS Release 10.1.

Espinosa, N. (2012). Impactos del paramilitarismo en la región Urabá/Chocó 1998-2006. Claves para la lectura de las afectaciones colectivas. Ágora USB, 12(2), 289-327.

Espinosa-Manrique, M., y Cuvi, N. (2016). Las Pavas: dinámicas de un conflicto socioambiental relacionado con los agrocombustibles en Colombia. Ambiente y Desarrollo, 20(39), 83-100.

Finzi, G. (2017). El caso de Poligrow en Mapiripán, Meta: entre acaparamiento (ilegal) de tierras y capitalismo verde. Ciencia Politica, 12(24), 21-50.

Franco, J. (2012). La carrera mundial para hacer más "transparente" el acaparamiento de tierras. En Centro de Investigación para la Paz (ed.), Acaparamiento de tierras, el nuevo expolio (pp. 18-26). Fuhem.

Franco, V., y Restrepo, J. (2011). Empresarios palmeros, poderes de facto y despojo de tierras en el Bajo Atrato. En M. Romero (ed.), La economia de los paramilitares. Redes de corrupción, negocios y politica (pp. 269-356). Corporación Nuevo Arco Iris.

García, J., y Rivera, H. (2015). Intervención de la clínica jurídica sobre derecho y territorio en el caso de los campesinos de la hacienda Las Pavas. Pontificia Universidad Javeriana.

García, P. (2014). Tierra, palma africana y conflicto armado en el Bajo Atrato chocoano, Colombia. Una lectura desde el cambio en los órdenes de extracción. Estudios Socio-Jurídicos, 16(1), 209-244.

Gellert, P. (2015). Palm oil expansion in Indonesia: land grabbing as accumulation by dispossession. States and Citizens: Accommodation, Facilitation and Resistance to Globalization. Current Perspectives in Social Theory, 34(1), 65-99.

Gilbert, J. (2017). Land grabbing, investments \& indigenous peoples'rights to land and natural resources: case studies and legal analysis. International Work Group for Indigenous Affairs.

Glassman, J. (2006). Primitive accumulation, accumulation by dispossession, accumulation by 'extra-economic' means. Progress in Human Geography, 30(5), 608-625. 
Gobierno de Colombia. (1993, 27 de agosto).Ley 70 de 1993. https://www.mininterior.gov.co/la-institucion/normat ividad/ley-70-de-1993-agosto-27-por-la-cual-se-desarrolla-el-articulo-transitorio-55-de-la-constitucion-politic a

Gobierno de Colombia. (1996). Resolución 0286 de 1996.

Gobierno de Colombia. (2012). Decreto 902 de 2012.

Goebertus, J. (2008). Palma de aceite y desplazamiento forzado en zona Bananera: "trayectorias" entre recursos naturales y conflicto. Colombia Internacional, 67(1), 152-175.

Gómez, C., Sánchez-Ayala, L., y Vargas, G. (2015). Armed conflict, land grabs and primitive accumulation in Colombia: micro processes, macro trends and the puzzles in between. The Journal of Peasant Studies, 42(2), 255-274.

Grajales, J. (2011). The rifle and the title: paramilitary violence, land grab and land control in Colombia. Journal of Peasant Studies, 38(4), 771-792.

Grajales, J. (2016). Le droit, la violence et la terre : le rôle de l'État dans l'accaparement foncier en Colombie. Cahiers des Amériques latines, 81(1), 35-51.

Hallam, D. (2009). International Investments in agricultural production. En M. Kugelman y S. Levenstein (eds.), LAND GRAB? The Race for the World's Farmland (pp. 25-38). Wodrow Wilson International Center for Scholars.

Harvey, D. (2010). A Companion to Marx's Capital. Verso.

Hurtado, M., y Pereira, C. (2011). Legitimidad empresarial, conflicto de tierras y producción palmera en Colombia. Revista de relaciones internacionales, estrategia y seguridad, 6(2), 91-110.

Instituto Colombiano de Desarrollo Rural. (2012). Caracterización jurídica y saneamiento de los territorios colectivos de curvaradó y jiguamiandó.

Instituto Geográfico Agustín Codazzi. (2018). Sistema de Información Geográfica para la planeación y el ordenamiento territorial. https://sigot.igac.gov.co/

Marín-Burgos, V., y Clancy, J. (2017). Understanding the expansion of energy crops beyond the global biofuel boom: evidence from oil palm expansion in Colombia. Energy, Sustainability and Society, 7(21). https://doi.org/10.1 186/s13705-017-0123-2

Marx, K. (1867). Capital. A Critique of Political Economy. Progress Publishers.

Matondi, P., Havnevik, K., y Beyene, A. (2011). Biofuels, land grabbing and food security in Africa. The Nordic Africa Institute.

Maughan, M. (2011, 6-8 de abril). Land Grab and Oil Palm in Colombia. Documento presentado en la Conferencia internacional sobre acaparamiento global de tierras. Documento presentado en la International Conference on Global Land Grabbing Institute of Development Studies, Universidad de Sussex. http://www.future-agricultures .org/wp-content/uploads/pdf-archive/Mark_Maughan.pdf

Mignorance, F., Minelli, F., y Le Du, H. (2004). El cultivo de la palma Africana en el Chocó. Legalidad ambiental, territorial y Derechos Humanos. Human Rights Everywhere.

Moore, D. (2004). The Second Age of the Third World: from primitive accumulation to global public goods? Third World Quarterly, 25(1), 87-109.

Moyo, S., Praveen, J., y Yeros, P. (2012). Imperialism and Primitive Accumulation: Notes on the New Scramble for Africa. Agrarian South: Journal of Political Economy, 2(1), 93-119.

Mujica, C. (2010). Evolución del sector palmicultor. Universitaria de Investigación y Desarrollo.

Ocampo, S. (2009). Agroindustria y conflicto armado: El caso de la palma de aceite. Colombia Internacional, 70(1), 169-190.

Perfetti, J., y Saavedra, V. (2017). Acuerdo de Paz y Decreto Ley de Tierras. Economía y Política. Fedesarrollo, 69(1), 1-10. https://www.repository.fedesarrollo.org.co/bitstream/handle/11445/3420/EyP_No_69.pdf?sequence= $1 \&$ isAllowed $=\mathrm{y}$ 
Piñeros, R. (2016). La territorialización del agronegocio de la Palma de Aceite y la Caña de Azúcar en la altillanura colombiana. Aportes para el estudio de sus efectos a las condiciones de trabajo de los asalariados rurales. https://w ww.doi.org/10.13140/RG.2.1.2214.2321

Poligrow invertirá US\$ 18 millones en planta extractora. (2018, 5 de enero). El Tiempo. https://www.eltiempo.com/ economia/empresas/poligrow-invertira-us-18-millones-en-planta-extractora-en-el-meta-168420

Poligrow sembrará 8.000 hectáreas más en Mapiripán. (2017, 28 de julio). Portafolio. https://www.portafolio.co/neg ocios/empresas/poligrow-sembrara-ocho-mil-hectareas-en-mapiripan-508213

Rey Sabogal, C. (2013). Análisis espacial de la correlación entre cultivo de palma de aceite y desplazamiento forzado en Colombia. Cuadernos de. Economía, 32(61), 683-718.

Rodríguez, I. (2014). Despojo, baldíos y conflicto armado en Puerto Gaitán y Mapiripán (Meta, Colombia) entre 1980 y 2010. Estudios Socio-Jurídicos, 16(1), 315-342.

Salinas, Y. (2012). El caso de Colombia. En F. Soto y S. Gómez (eds.), Dinámicas del mercado de la tierra en América Latina y el Caribe (pp. 179-208). Food and Agriculture Organization.

Salinas, Y., Álvarez, P., Van Dorp, M., Rácz, K., y Kuijpers, K. (2015). Reconquista y despojo en la Altillanura. El caso Poligrow en Colombia. Indepaz y Somo.

Sassen, S. (2010). A savage sorting of winners and losers: contemporary versions of primitive accumulation. Globalizations, 7(1), 23-50.

Seeboldt, S., y Salinas, Y. (2010). Responsability and sustainability of the palm oil industry. Are the principles and criteria of the RSPO feasible in Colombia? Oxfam.

Seo, K., y Rodríguez, N. (2012). Land Grab, Food Security and Climate Change: A Vicious Circle in the Global South. En N. Chhetri (ed.), Human and Social Dimensions of Climate Change. https://www.doi.org/10.5772/50876

Thomson, F. (2011) The agrarian question and violence in Colombia: conflict and development. Journal of Agrarian Change, 11(3), 321-356.

Ulas, O. (2014). Primitive accumulation, new enclosures, and global land grabs: a theoretical intervention. Rural Sociology, 79(1), 104-131.

Ulas, O. (2017). Between equal rights: Primitive accumulation and capital's violence. Political Theory. Research Collection School of Social Sciences, 46(6), 885-914.

White, B. (2012). Transacciones de tierras, desposesión y el futuro de la agricultura. En Centro de Investigación para la Paz (ed.), Acaparamiento de tierras, el nuevo expolio (pp. 18-26). Fuhem.

\section{Notas}

* Artículo de investigación

\section{Licencia Creative Commons CC BY 4.0}

Cómo citar este artículo: Torres Mora, Á. G. (2020). Acumulación primitiva y acaparamiento de tierras en Colombia. Dinámicas del desarrollo. Papel Político, 25. https://doi.org/10.11144/Javeriana.papo25.apat 